\title{
Abstracts
}

\section{Survival and Health at the Oldest Ages Tony Warnes}

John R. Wilmoth. I995. Are mortality rates falling at extremely high ages? An investigation based on a model proposed by Coale and Kisker. Population Studies, 49, 28 I-295.

The relationship between increasing years of age after the ninth decade of life and increments of mortality risk has recently attracted the intense attention of some demographers. The special fascination is prompted partly by the healthy survivor hypothesis (that people who attain exceptionally high ages are selectively vigorous), partly by the utilitarian interest in projecting trends in healthy versus unhealthy life expectancy, and partly by the search for evidence that the maximum human life span is either greater than the scientific consensus asserts (i.e. around $12 \mathrm{I}$ years), or that it is increasing. Like many other disputed fields, competing claims survive partly because of the scarcity or unreliability of data.

The author, from the Department of Demography at the University of California, Berkeley, begins with the question, 'If there are limits to the continued reduction in human mortality, how do they operate?' and then considers the difficulties of establishing the extent and pace of recent reductions in late-age mortality: namely random variation among small numbers, and inaccurate age reporting through the heaping of zeros and fives and age-exaggeration. To adjust for ageexaggeration in the United States, Coale and Kisker (1990) proposed a model which assumes (a) that the rate of increase in age-specific mortality above 85 years declines as a linear function of age, and (b) that the level of mortality at age $i$ I o years is constant across time and in various populations. Wilmoth critically examines these assumptions with data from Sweden and Japan for I97I-9o. Only the pattern for Japanese men deviates substantially from the linear function.

Coale and Kisker regarded United States mortality rates for ages over 85 years as unreliable, hence their second assumption. Wilmoth has more confidence in his data and uses alternative procedures for fitting functions to (a) the Swedish empirical death rates from 85 to ioo years for I 896-I 900 to $1986-90$, and (b) the Japanese death rates for the same ages from $195^{\mathrm{I}-55}$ to $1986-90$. Additionally, he calibrates 
functions using the empirical rates for older ages, to explore the possibility that their rate of change differs and whether there is evidence that the rate at i Io years has not changed through time. 'The results of this exercise are mixed' (p. 288). In Sweden and Japan, the implied level of mortality at i io years appears to have declined for women but not for men. The female improvement of about one-third compares favourably with the improvement attained through 9I-Ioo years of age, but the annual rate of 0.4 per cent is lower than the 'middle' assumption employed in United States population projections of one per cent. The Japanese functions are less consistent - they vary with the fitting procedure-which Wilmoth attributes partly to unreliable data. He argues that the Japanese results to a large extent reproduce the Swedish findings, and ends with a truism and a qualified conclusion. 'When accurate mortality data are available above age 85 , it is not necessary to fit the Coale-Kisker model using an assumed (mortality rate for I I o years)' and 'Swedish and Japanese data suggest that (implied) mortality rates at extremely high ages (around II years) may have declined in this century for women, but probably not for men' (p. 295).

\section{COMMENT}

The article has much detailed technical exposition but is clearly explained and has fascinating summaries and discussions. It continues a strong research field which is reported mainly in demographic and biometric journals (Cage I990, Manton et al. I 99 I, Riggs and Millecchia I992, Thatcher 1992). Social gerontologists should be aware how few reliable data there are on mortality at the most advanced ages and that, even in those countries with good data, they cover few decades. Like several other of the most assiduous investigations of the available data, Wilmoth finds no evidence that mortality trends at the very oldest ages are radically different from those in earlier old age.

\section{References}

Cage, T. B. I99o. Variations and classification of human age patterns of mortality: analysis using competing hazards models. Human Biology, 62, 5, 589-6 I 7 .

Coale, A. J. and Kisker, E. E. 1990. Defects in data on old-age mortality in the United States: new procedures for calculating mortality schedules and life tables at the highest ages. Asian and Pacific Population Forum, 4, 1, 1-31.

Manton, K. G., Stallard, E. and Tolley, H. D. 1991. Limits to human life expectancy: evidence, prospects and implications. Population and Development Review, 17, 4, $603-637$.

Riggs, J. E. and Millecchia, R. J. 1992. Using the Gompertz-Strehler model of aging 
and mortality to explain mortality trends in industrialized countries. Mechanisms of Ageing and Development, 65, 21 7-228.

Thatcher, A. R. 1992. Trends in numbers and mortality at high ages in England and

Wales. Population Studies, 46, $4 \mathrm{I} \mathrm{I}-426$.

Margaret R. Bone, Andrew C. Bebbington, Carol Jagger, Kevin Morgan and Gerry Nicolaas. 1995. Health Expectancy and its Uses. Her Majesty's Stationery Office, London, 90 pp., $\mathcal{E}^{\text {I } 4}$, ISBN o 1 I 7 020052.

This study funded by the United Kingdom Department of Health 'reviews the main methods of calculating healthy life expectancy, provides examples of a range of applications of the indicator, and draws conclusions about suitable methodologies for the future' (p. I). The report has fifteen short chapters, with more on the contexts of late-age mortality decline, the debate on the 'compression of morbidity', and developments in the prevention and treatment of chronic disease, than on international research on mortality and morbidity trends.

The core of the study begins in chapter 4, 'Existing methods of calculating health expectancy'. 'Two main ways are used... the Sullivan (197 I) method, and the multi-state life table method (Manton and Stallard 1988). Sullivan's method is the most commonly used because it is applied to cross-sectional data on the prevalence of disability which are widely available from regular surveys and censuses, for example, the General Household Survey (GHS), the English Health Survey and the I99 I Census' (p. 9). In this report it is used for all estimates excepting those in Chapter I I.

Chapter 5 reproduces Bebbington's (199I) estimates using the GHS questions on limiting long-standing illness (LLSI), and Chapter 6 extends them through 1992. The former states that 'the trend in the ratio of health expectancy to life expectancy ... indicates no compression of morbidity' (pp. $15 / 18$ ) and the latter that 'overall there has been a relentless increase in the expectation of unhealthy life. For men it rose from II.7 years in 1976 to 14.0 years in 1992; for women the corresponding increase was from 14.1 to 17.3 years. This seems to support the pessimistic view that we are likely to experience an expansion of morbidity and a consequent increased demand for health and social services as the population continues to age' (p. 24). On the other hand, when the Katz et al. (1963) Activities of Daily Living Scale is applied to the responses to the GHS disability questions, 'health expectancy derived from these measures of mobility has increased in identical proportions to total life expectancy, with the result that the 
proportion of remaining years of life free of these disabilities has almost stabilised (during I 976-9I)' (p. 30). The British results are compared with those from other nations, and various reasons for the discrepancies are discussed.

Chapter 7 examines variations in mean life expectancy at birth and at age 65 years, and in the prevalence of LLSI geographically (by official Regions, Regional Health Authorities, Metropolitan Boroughs and Counties of England and Wales) and by ethnic groups. LLSI is standardised over nine age groups to produce an intriguing comparative measure, but it is surprising that it is again presented without clear qualification as a 'disability rate' (Table 7.2, p. 35). Chapter 8 tackles the very difficult task of estimating gains in disability-free life expectancy from the complete elimination of specified diseases, using a simple method from Australia (Mathers, I99I). 'The gain from the elimination of any one condition is surprisingly small: it would be smaller still if multiple causes of disability/death had been taken into account. Elimination of circulatory diseases would lead to the greatest gain in life expectancy and hence... in life expectancy' (p. 47).

Chapters Io and I I compare health expectancies calculated from both cross-sectional and longitudinal data generated by the Nottingham Longitudinal Study of Activity and Aging (NLSAA) and the Melton Mowbray Ageing Project (MMAP), using a variety of definitions of health. The former interviewed 1,042 people living in the community in I 985 and completed a follow-up interview with 690 in I 989 . The latter comprises two cross-sectional surveys in Ig8I ( $N=$ $\mathrm{I}, 203)$ and $\mathrm{I} 988\left(\mathrm{~N}=\mathrm{I}, 579\right.$, of who 440 were survivors from the $\mathrm{I}_{98} \mathrm{I}$ panel). By linking the cross-sectional prevalence data with national mortality schedules, estimates are made of life expectancies with and without a range of specified disorders. Chapter I I applies the multistate life table method to the MMAP and NLSAA data, although the small sample sizes precluded the consideration of more than two health states... 'healthy' and 'unhealthy'. The intricate results are difficult to summarise, but it is concluded that ' $20 \%$ of a 70 years old woman's remaining life and $35 \%$ of a man's were free of mental and physical disability, incontinence and with good perceived health' (p. 67).

\section{COMMENT}

The report presents diverse material: a textbook's topic introductions, technical expositions, empirical estimates, advocacy for further research, and an extensive bibliography. It must have been difficult to plan and write, to be simultaneously accessible to a policy audience and 
an advance in a methodologically-difficult and data-starved field. The achievement is considerable, not least in bringing together in one volume accounts of so many approaches to the estimation of healthy and unhealthy states and years, and in showing how difficult it is to model recent change let alone to develop projections.

Government health ministries and influential physicians have high expectations for the practical utility of estimates and projections of Healthy Active Life Expectancy (HALE). There are considerable incentives to researchers to produce sound estimates, and dangers attend. The authors of this report almost wholly avoid hyperbole and alarmist constructions of 'a medical avalanche by lengthening life beyond a capacity to preserve its quality', and apply appropriate rigour and caution in their demonstrations and interpretations. The material should however be subject to widespread critical attention for the estimates are unusually prone to misuse. $M y$ caution can be illustrated by one query: why has so little attention been given to the temporal stability or validity of LLSI responses? It is known that positive responses are affected by exogenous social circumstances, as shown by the responses to the equivalent 1991 population census question by males aged around retirement age (Charlton et al. 1994). The rising prevalence over time in the GHS responses is unlikely to be simply related to intrinsic health. The 'limiting illness' data are unusually accessible and comprehensive, and they provide invaluable cross-sectional data, but I am deeply suspicious of any temporal trend established from self-report health questions.

\section{References}

Bebbington, A.C. 1991. The expectation of life without disability in England and Wales. Population Trends, 66, 26-29.

Charlton, J., Wallace, M. and White, I. I 994. Long term illness: results from the I991 census. Population Trends, 75, 18-25.

Katz, S., Ford, A. B., Moskowitz, R. W., Jackson, B. A. and Jaffe, M. W. I963. Studies of illness in the aged. The index of ADL: a standardized measure of biological and psychosocial function. Journal of the American Medical Association, 185, 914-919.

Manton, K. G. and Stallard, E. 1988. Chronic Disease Modeling: Mathematics in Medicine No. 2, Charles Griffin, London.

Methers, C. D. 1991 . Health Expectancies in Australia, 1981 and 1988 , Australian Institute of Health, Canberra.

Sullivan, D. F. 1971. A single index of mortality and morbidity. HMSA Health Report, 86, 347-354.

Department of Health Care for Elderly People, University of Sheffield 